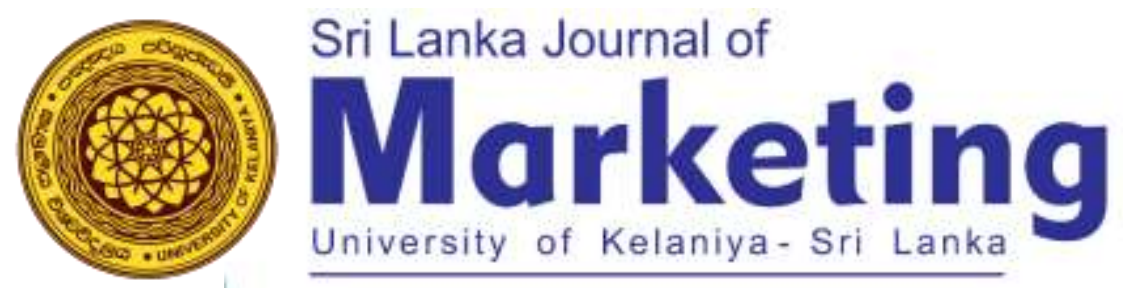

\title{
Conceptual Review on Apparel Disposal Behaviour of Consumers
}

\author{
N.W.O.K.D.S.P. Nanayakkara \\ Assistant Lecturer, University of Kelaniya, Sri Lanka \\ 2017_sonali@kln.ac.lk
}

\begin{abstract}
Conserving resources for future generations through sustainable consumption presents both a unique challenge and an opportunity for individuals in contemporary society. Sustainable consumption which is becoming a growing trend in the society advocates encourage individuals in affluent, developed countries to shift toward consumption that is more socially and ecologically sustainable. These advocates suggest educating consumers on environmental, social, and economic preservation as a means to influence consumption behaviors. As a subsection of general consumption, sustainable consumption also includes acquisition, use, and disposal behaviors. Investigation into disposal is necessary because it provides additional insight into the behaviors of consumers. The study of disposal is of particular importance in the context of apparel because the very nature of the product differs from typical durable and non-durable goods. In apparel consumption, the term disposal refers to whether a garment is simply thrown away, resold, reused, or recycled. Alongside, this study attempts to identify the different types of consumer apparel disposal behaviors and the underlying factors that affect clothing disposal behaviors. Paper followed an extensive literature review to build a discussion on theoretical and empirical contents related to consumer apparel disposal behaviors. Paper attempts to appreciate the application of different types of disposal behaviors with particular reasons. The literature review was executed addressing to key sub contents related to apparel disposal behaviors. It reviewed journal articles as the main source of information to organize the contents with empirical justifications. Finally, paper discusses the concepts of environmental knowledge, motivation, subjective norms in apparel disposal and how these factors affect different types of disposal behavior.
\end{abstract}

Keywords: Apparel Disposal Attitudes, Apparel Disposal Behavior, Apparel Disposal Motivations, Environmental Apparel Knowledge 


\section{INTRODUCTION}

Sustainability has been a significant topic discussed in several areas of literature such as environment and economy. Clothing consumption can be observed as a part of sustainability issue, in which consumers feel responsible for sustainable consumption by disposing their used clothing (Connell \& Kozar, 2014). However, it may be a burden for consumers to sustainable consumption that people cannot make use of their belongings such as clothing which they get bored of very quickly or their worn clothing and they cannot exhibit recycling behavior (Aydin, 2017). Disposal of used clothing is a quite difficult decision for consumers as fast fashion is highly important for consumers (Kang \& Schoenung, 2006). Moreover, Paden \& Stell (2005) highlighted that disposal occurs when the consumer decides to remove items from the home by throwing away, passing along, or selling their possessions. Disposal is a critical step where past research has shown that consumers may make these disposal choices without awareness of the societal and environmental implications of these choices (Frings, 2004). The first step in this process is the prompt or reason for the disposal action.

On that account, as explained by Hawley (2006), apparel disposal can be identified as how consumers temporarily or permanently remove apparel from the inventory and how consumers view apparel defines disposal actions that follow. Shim (1995) explains four major methods of apparel disposal behavior among consumers namely resell, donate, reuse, and discard. Resell describes when a consumer sells his or her used apparel for currency (Shim, 1995). The term donate is often used interchangeably with recycling in apparel disposal literature and portrays what happens when a person gives away his or her apparel (Ha-Brookshire, 2009; Shim, 1995). Reuse explains when apparel is still utilized by a consumer, but for a different purpose other than for which it was originally intended (Domina et al., 2002). Lastly, discard refers to when apparel is thrown away, abandoned, or destroyed in a manner that will eventually contribute to textile waste (Domina et al., 2002). Goudeau (2014) explained the underlying reason for apparel disposal behavior as environmental apparel knowledge, apparel disposal motivation, apparel disposal attitude and subjective norms. Further explains research on the consumer apparel disposal behavior is still very limited and confines itself mainly to the western countries in the world (Domina \& Koch, 2002). In this study it is decided discuss the purpose of the study and methodology, literature review and the discussion with conclusion and future directions.

\section{PURPOSE OF THE STUDY}

In general, in consumer decision making process models, consumers go through three stages acquisition, usage, and disposition in consuming a product. Although numerous studies have been conducted regarding acquisition and usage, very little research has been conducted regarding the disposition stage (Shim, 1995). 
Many researches have been explored the re-use and utilization of paper, glass and plastic however only a few have examined textiles although textiles represent one of the untapped consumer commodities with strong reuse and recycling potential (Koch \& Domina, 1999). Therefore, this paper attempts to investigate different types of consumer apparel behavior in relation to apparel disposal. Further it contributes to wider the existing knowledge as a theoretical review is carried out to identify relevant contingency factors. Thus, identification of different types of consumer apparel behaviors and the underlying motivational factors will help people and organizations who are looking to recognize the role of consumption sustainability as an integral component of their business strategy (Morgan \& Birtwistle, 2009). Accordingly, the author attempts to further investigate how empirical evidences are found discussing the drives which lead for consumer apparel disposal behavior and different types of disposal behaviors shown by apparel consumers.

\section{METHODOLOGY}

This paper follows a deductive approach in which arguments and explanations are mainly supported by empirical evidences and associated theoretical contents. It is attempted to review empirical thoughts as an organized content on different types of disposal behaviors shown by apparel consumers and the underlying reasons different contexts and literature review was employed as the main research tool. Finally concluded the main remarks though suggesting key insights for the future research directions.

\section{LITERATURE REVIEW}

This paper presents the literature review by mainly focusing on empirical overview consumer apparel disposal behavior whilst explicit consideration is made towards the drives which lead for consumer apparel disposal behavior and different types of disposal behaviors shown by apparel consumers. Additionally, content describes how consumer apparel disposal behavior appeared as denoted in empirical studies.

\subsection{Apparel Disposal Behavior}

A consumer's disposal behavior is explained as the consumer's behavior and decision making during his or her unused product disposition stage (Yee, Hassan, \& Ramayah, 2016). Apparel disposal includes how consumers temporarily or permanently remove apparel from their inventory (Paden et al., 2005). The first research to discuss apparel disposal as a part of the apparel consumption process was written by Winakor in 1969, in which suggests apparel consumption consists of acquiring a garment, placing it in inventory, and then disposing of it (Goudeau, 2014). In reference to disposal, Winakor (1969) further stated that, fashion can cause a person to discard an otherwise serviceable garment and buy a new one. According to Disposition Decision Taxonomy theory consumers have three options after using a product namely keeping the product, disposing the product temporarily, or disposing the product 
permanently which become a key research topic for some researchers (Albinsson \& Perera, 2009 ; Domina \& Koch, 2002 ; Hiller, 2010). In apparel disposal, consumers keep their garments until a decision is made to remove possession. While some consumers accomplish this temporarily by renting or loaning their apparel, others to get rid of apparel permanently (Goudeau, 2014).

As per the findings of Bianchi \& Birtwistle (2012), apparel disposal behavior of consumers involves few major methods such as reusing used clothing, recycling, donating it to charities, giving it away, giving it to a second-hand store, eliminating it completely, and so on. But consumers, prefer a faster and more convenient method of disposing their used or unwanted apparel where as they often choose to discard apparel rather than to engage in other more eco-friendly alternatives (Joung \& Park-Poaps, 2013). Therefore, Shim (1995) explains four major methods of apparel disposal behavior among consumers namely resell, donate, reuse, and discard.

Resell describes when a consumer sells his or her used apparel for currency (Shim, 1995). The term donate is often used interchangeably with recycling in apparel disposal literature and portrays what happens when a person gives away his or her apparel (Ha-Brookshire, 2009; Shim, 1995). Reuse explains when apparel is still utilized by a consumer, but for a different purpose other than for which it was originally intended (Domina et al., 2002). Lastly, discard refers to when apparel is thrown away, abandoned, or destroyed in a manner that will eventually contribute to textile waste (Domina et al., 2002). Hence, this study aims to shed some insight into the $d$ ifferent methods of apparel disposal and the underlying factors that affect the clothing disposal behavior. Each disposal method is explained in further detail in the subsequent sections.

\subsection{Resell}

Selling of used goods for economic benefits is well understood. Studies have found that monetary incentives or rewards encourage pro-environmental behaviors such as recycling and reusing (Joung et al., 2013). For example, Jacobs and Bailey (1982) found that any type of incentive, especially monetary incentives, increased consumer recycling behavior. Apparel resale takes place through direct or indirect channels in conventional and virtual settings through consignment/vintage stores or online to generate income (Paden et al., 2005). Due to recent popularity of online shopping, consumers use online auctions like eBay, which allows selling goods such as vintage, used, new and even celebrity clothing items directly to other consumers. According to Neislsen ratings, eBay's clothing site has more visitors than Victoria Secret's (Lee,2007). Reselling via indirect channel involves using a consignment or resale intermediary to assist with redistribution. Consignment and resale stores both sells used clothing, but take different approaches to secondhand retailing (Paden et al., 2005).

Researchers have recognized factors related to clothing disposal behaviors and found that consumers resell unwanted clothing for monetary gains (Jacobs et al., 1982). As suggested by Fletcher (2013), 
selling unwanted but reusable textiles to merchants provides a likely source of income while reducing the cost of waste disposal and benefits to protect the environment. In addition, consumers' motivation to sell clothing is determined by the value to others of their unwanted garments (Claudio, 2007).

\subsection{Donate}

Apparel donation is carried out using a variety of redistribution channels. In its simplest form, donation involves passing apparel items on to one's friends, family members, or other acquaintances (Paden et al., 2005). Paden et al., 2005 further explained that apparel that is not donated directly to an individual is usually redistributed through charitable organizations and thrift stores. Garments that are offered to charitable organizations, such as the Red Cross, are used to clothe people who are in need at little to no cost (Paden et al., 2005). Consumers who choose to donate apparel using the thrift store redistribution channel have the option of giving their items to either a for profit or nonprofit business (Goudeau, 2014). Donation bins are a primary means of collection allowing consumers the convenience of 24 hour drop off. The consumer's familiarity with these bins has allowed other for-profit organizations to also enter the market for clothing collection (Hawley, 2006).

The main influences to donate fell into two categories as the items were thought of as in physically appropriate condition or a step above throwing it in the trash which means the clothes are in a good enough condition not worn and someone else can use (Bianchi et al., 2012). Further explained by Bianchi et al. (2012) the first reason to donate clothes is that the quality of the cloth is thought to be with a good value to someone but not the one it belongs. The second influence to be a donor is that considering donation as a positive alternative to throwing items in the garbage this may indicate a lack of evaluation process (Goudeau, 2014). Although most consumers recognize that textile donating is a disposal option, many cite the inconvenience of having to take clothing to a recycling facility as a major hindrance to participating in donation programs (Domina et al., 2002). In response, organizations and government municipalities are working to make donating more convenient than ever (Morgan \& Birtwistle, 2009).

\subsection{Re use}

Apparel reuse involves altering a garment to be employed for a new purpose or function (Shim, 1995). Some consumers take old apparel and use it to create cleaning wipes or rags for around the house (Koch et al., 1999). Others find more creative ways to reuse their old apparel. New products that can be made using old apparel include pillows, dolls and puppets, quilts, rugs, and reusable grocery bags. Old apparel may also be converted into new garments, accessories, or footwear through a makeover or restyling (Rasband, 2006). In the study, Koch et al., (1999) also indicated that consumers often modified apparel or reused it as rags if the garment was worn out or damaged in some way. A garment being old or out of style was the least chosen reason for apparel disposal. According to Domina et al., (2002) makeovers 
involve completely reconstructing apparel to make an entirely new garment. In most instances, a larger piece of apparel is transformed into a smaller piece of apparel or components of various garments are combined to create a new garment. Restyling differs from a makeover in that only a portion of a garment is changed. For instance, a long shirt can be cut into a cropped style. Reasons for reuse as rags included that apparel items were damaged or worn out (Bianchi et al., 2012). Connell et al., 2014 stated that the environment and sustainability should be the focal points of organizational marketing efforts to promote reuse because environmental apparel knowledge, environmentally-focused reuse motivation, and attitude toward sustainable apparel disposal were found to be positive precursors to reuse behavioral intention. Environmental apparel knowledge and attitude toward sustainable apparel disposal were negative precursors to apparel discard intentions. Thus, efforts to discourage the use of discard should emphasize environmental repercussions and highlight alternative apparel disposal methods. (Claudio, 2007)

\subsection{Discard}

The last apparel disposal option investigated in this study is discarding. Some people have the tendency to choose the discard method purely out of convenience (Domina et al., 2002). The discard method is also commonly chosen when consumers feel a garment lacks value or the effort to dispose of it using a different method such as resell, donate, or reuse outweighs the benefit of diverting waste from the landfill (Paden et al., 2005). Individuals are often unaware that even the oldest, dirtiest garments can be diverted from the landfill through donation facilities or textile recycling companies (Hawley, 2006; Shim, 1995). When consumers choose to discard apparel and other textile items, it contributes to rising levels of textile waste in landfills (Hawley, 2006).

However, apparel may not be at the end of its usefulness when it is no longer desired by the consumer, which results in a variable rate for disposal. Some items that can no longer be worn due to excessive wear and tear may be discarded by consumers who assume that no other human could wear the clothing (Clark \& Palmer, 2004). For some, disposal may be viewed as the only option for discarding clothing. Reasons for discarding clothing may be related to concerns over the hygiene of previous owners and overall cleanliness of the item (Gregson \& Crewe, 2003). For instance, VeVerka (1974) investigated attitudes and practices regarding active, inactive, and discarded garments, and their attitude toward the economic value of storage and garments not in active use. In her study, the basic premise was that inactive or discarded clothing is a source of waste. It was concluded that garments may be discarded when the current use value provided by the garment is less than the current costs of the garment and when the cost of keeping the garment exceeds the costs of disposing of the garment. 


\subsection{Environmental Apparel Knowledge and Apparel Disposal Behavior}

Arcury \& Johnson (1987) defined environmental knowledge as factual information that individuals have about the environment, the ecology of the planet, and the influence of human actions on the environment. Studies on the relationship between environmental knowledge and environmentallyfriendly behaviors have found a positive relationship between the concepts (Dispoto, 1977).

While studies on environmental knowledge in general have noted a link to environmentally-friendly behavior, much of the research assessing environmental knowledge of the apparel industry has yielded inconsistent findings. Some researchers have found that environmental apparel knowledge, defined as one's awareness of the impact of apparel products on the natural environment (Kim H. , 1995), has little to no effect on consumption practices. Kim \& Damhorst, (1998) studied environmental apparel knowledge in relation to apparel consumption and environmentalism.

According to Sampson (2009), consumers that have greater levels of environmental knowledge are more likely to feel motivated to partake in environmentally-friendly behaviors. Supporting the Sampson's theory as per the findings of Goudeau (2014) consumer knowledge of the environment regarding apparel production have a great on impact motivation to resell, donate, and reuse apparel. It was also predicted that a weak relationship would be shown between environmental apparel knowledge and motivation to discard apparel. The associations between environmental apparel knowledge and apparel disposal motivation were all supported except in the instance of resell, where no significance was found in the connection between these factors. The absent relationship between environmental apparel knowledge and motivation to resell is inconsistent with Sampson's supposition, but falls in line with Shim's (1995) statement that there is a lack of relationship between apparel resale and environmentalism. Perhaps the environment is not a factor people consider when they are deciding whether or not they should resell their items. Other factors, such as economic gain, may have a greater influence on one's motivation to resell apparel.

\subsection{Apparel Disposal Motivation and Apparel Disposal Behavior}

Motivations are the internal reasons or forces that activate a person's behavior (Babin \& Harris, 2010; Solomon, 2010). They are of interest in consumer behavior research because they provide the intended reason for a person's behavior (Babin et al., 2010).

Apparel disposal motivations are the underlying and internal reasons or forces that activate apparel disposal behavior (Babin et al., 2010; Shim, 1995; Solomon, 2010), have been explored in prior studies. Shim (1995) studied apparel disposal and determined that consumers were motivated by economic, environmental, charitable, awareness, or convenience reasons. Similarly, Joung et al., (2013) researched 
apparel disposal motivations and found that environmental, economic, charity, and convenience concerns were factors that influenced apparel disposal behaviors.

As stated by Goudeau (2014) apparel disposal motivation to resell, donate, reuse, and discard would influence to resell, donate, reuse, and discard disposal behaviors respectively. The level of motivation to engage in a particular apparel disposal behavior corresponded with the intention to engage in the apparel disposal behavior where a person who was highly motivated to reuse apparel would also have high intentions to reuse apparel. (Fitzmaurice, 2005)

\subsection{Apparel Disposal Attitude}

Attitudes are a learned predisposition to behave in a consistently favorable or unfavorable way with respect to a given object (Schiffman, 2010). The authors explained that attitudes are learned because they are acquired through experience, secondhand information, and other forms of exposure. They are consistent in that they are what stimulate consumers to behave in a reliable manner (Babin et al., 2010; Schiffman et al., 2010). Attitudes are enduring over long periods of time (Solomon, 2010), but should not be considered permanent because they are subject to change (Schiffman et al., 2010).

Dunlap \& Van Liere (1978) stated that many apparel disposal studies that evaluate attitude have specifically focused on environmental attitudes. An environmental attitude is a person's negative or positive beliefs about the relationship between individuals and the environment. Shim (1995) discovered that environmental attitude was an influencer of certain disposal behaviors. In particular, the researcher revealed that environmental attitude had a positive effect on donate and reuse behaviors, but a negative effect on discard behaviors. Resale behaviors were not predicted by environmental attitude in Shim's study. Koch et al., (1999) also found that higher levels of environmental attitude had a positive relationship with donate and reuse as textile disposal methods, but had non-significant results for resale behaviors. Prior findings were further supported in the most recent research, which was conducted by Joung et al., (2013). As per the findings of Goudeau (2014), apparel disposal attitude influence the intention to use the more sustainable disposal methods like resell, donate, and reuse, but does not influence intention to discard. Goudeau (2014), further indicated that there was no significant connection between apparel disposal attitude and intention to resell. Ha-Brookshire et al., (2009) specifically studied donation behaviors, found that consumer donation attitudes were not strongly associated with their donation intentions.

\subsection{Subjective Norms and Apparel Disposal Behavior}

Babin et al., (2010) explained that a consumer's subjective norms are based on his or her beliefs about a reference group. The authors stated that a reference group consists of individuals who have significant 
relevance for a consumer and who have an impact on the consumer's evaluations, aspirations, and behavior.

In the realm of apparel, little research has been conducted on subjective norms in relation to disposal behavior. The studies that have explored the two concepts have inconsistent results. While HaBrookshire et al., (2009) found that social pressure did not have a strong association with the apparel intentions to donate, and Joung et al., (2013) observed that family subjective norms influenced resale and donation apparel disposal behaviors. The discrepancy in results from these studies can most likely be attributed to the fact that the researchers utilized different research approaches.Goudeau (2014) suggested that apparel disposal subjective norms have an influence on apparel disposal behaviours to use the resell, donate, and reuse apparel disposal methods. It was also predicted that apparel disposal does not have any familiarity to discard clothes.

\section{CONCLUSION AND FUTURE RESEARCH DIRECTIONS}

Although it has been a topic of interest since the 1970s, sustainable consumption has recently been positioned at the forefront of the apparel and retailing industries. Sustainable consumption, which is a subsection of general consumption, is inclusive of the acquisition, use, and discard phases of the apparel consumption process (Jacoby, Berning, \& Dietvorst, 1977; Winakor, 1969). The acquisition and use components of the apparel consumption process have been extensively covered in previous studies (Mohr, Webb, \& Harris, 2001). However, the subject of apparel disposal has only gained popularity in recent years (Birtwistle \& Moore, 2007). Apparel disposal is a timely research topic because textile waste rates are steadily increasing throughout. The evolution of fast fashion retailing, which typically involves selling garments made with cheaper materials at a lower price, is believed to be a major contributor to these rising waste levels (McLaughlin, n.d.). The negative effects of fast fashion on disposal consumption behaviors are often suggested in apparel studies (Bianchi et al., 2012; Birtwistle et al., 2007; Claudio, 2007; Joung et al., 2013; Morgan et al., 2009), but research specifically investigating this implication is scarce. Therefore, the overall goals of this study were to assess apparel disposal antecedents and identify the commonly used apparel disposal methods. As per the findings of Bianchi et al., (2012), apparel disposal behavior of consumers involves few major methods such as reusing used clothing, recycling, donating it to charities, giving it away, giving it to a second-hand store, eliminating it completely, and so on. But consumers, prefer a faster and more convenient method of disposing their used or unwanted apparel where as they often choose to discard apparel rather than to engage in other eco-friendlier alternatives (Joung et al., 2013). Therefore, Shim (1995) explains four major methods of apparel disposal behavior among consumers namely resell, donate, reuse, and discard. Hence, this study aims to shed some insight into the different methods of apparel disposal and the underlying factors that affect the clothing disposal behavior. 
Motivations related to economics and the environment were collectively found to have the greatest influence on intention to engage in resale behaviors while for donation, environmental apparel knowledge led to increased apparel disposal motivation (Bianchi et al., 2012). Reuse and discard are disposal behaviors that are not typically linked to a specific type of retail or apparel-disposal business (Domina et al., 2002). Still, research findings regarding these methods can be utilized by organizations and entities interested in preserving the environment and reducing textile waste. Organizational messages should promote apparel reuse and discourage apparel discard. The environment and sustainability should be the focal points of organizational marketing efforts to promote reuse because environmental apparel knowledge, environmentally-focused reuse motivation, and attitude toward sustainable apparel disposal were found to be positive precursors to reuse behavioral intention (Morgan et al., 2009).

Retailers should strive to influence their customers' disposal behaviors through educational marketing and programs that promote usage of the more sustainable disposal methods. Information on sustainable apparel disposal can be disbursed in-stores, via company websites, and through cooperative media partnerships. Fast fashion retailers should consider shifts toward more sustainable consumption to be an opportunity, rather than a burden.

This study contributes to the literature on apparel disposal behavior by addressing inconsistencies and gaps in previous literature on antecedents. Incorporation of the additional antecedents increased the predictive ability of all four apparel disposal behavior methods. Therefore, it is highly recommended that apparel disposal antecedent research be inclusive of knowledge and motivation factors, in addition to subjective norms. There is only a limited number of studies carried out on "Consumer apparel disposal behavior" and therefore to fill the literature gap more research studies, conceptual frameworks, articles need to be carried out on this regard. Researchers may conduct further research to dig more in order to identify underlying factors for consumer apparel disposal behavior and should bring out new suggestions to dispose used apparel with sustainable practices. In addition, fast fashion is promptly growing, dynamically and the need for apparel disposal becomes a problem. Conclusively, we emphasis the knowledge required on understanding the different methods of apparel disposal and the underlying factors that affect the clothing disposal behavior. 


\section{REFERENCES}

[1] Ajzen, I. \&. (1980). Understanding attitudes and predicting social behavi.

[2] Albinsson, P., \& Perera, B. (2009). From trash to treasure and beyond: the meaning of voluntary disposition. Journal of Consumer Behaviour, 340-353.

[3] Arcury, T., \& Johnson, T. (1987). Public environmental knowledge: A statewide survey. The Journal of Environmental Education, 31-37.

[4] Aydin, H. (2017). Used Clothing Disposal Behavior within the Scope of Sustainable Consumption. International Journal of Academic Research in Economics and Management Sciences .

[5] Babin, B. J. (2010). On the evaluation of structural equation models. Journal of the Academy of Marketing Science.

[6] Baker, J. (2011). An investigation of the motivations for second-hand clothing donation and purchase. North Carolina.

[7] Bianchi, C., \& Birtwistle, G. (2012). Consumer Clothing Disposal Behaviour. International Journal of Consumer Studies, 335-341.

[8] Birtwistle, G., \& Moore, C. (2007). Fashion clothing-where does it all end up? International Journal of Retail and Distribution Management.

[9] Clark, H., \& Palmer, A. (2004). Old Clothes, New Looks.

[10] Claudio, L. (2007). Waste couture: Environmental impact of the clothing industry. Environmental Health Perspectives.

[11] Connell, K., \& Kozar, J. (2014). Environmentally Sustainable Clothing Consumption: Knowledge, Attitudes, and Behavior. In Roadmap to Sustainable Textiles and Clothing . Manhattan.

[12] Dispoto, R. G. (1977). Interrelationships among measures of environmental activity emotionality, and knowledge. Educational and Psychological Measurement.

[13] Domina, T., \& Koch, K. (2002). Convenience and frequency of recycling implications for including textiles in curbside recycling programs. Environment and Behavior.

[14] Dunlap, R., \& Van Liere, K. (1978). The new environmental paradigm. Journal of Environmental Education, 19-28.

[15] Fitzmaurice, J. (2005). Incorporating consumers' motivations into the Theory of Reasoned Action. Psychology and Marketing, 911-929.

[16] Fletcher, K. (2013). Sustainable fashion and textiles. In Design journeys. London.

[17] Frings, G. (2004). Fashion: From concept to consumer. Upper Saddle River: Pearson Education.

[18] Goudeau, C. V. (2014). Ready to Tear? A Study on Fashion and Consumer Disposal Behavior. 
[19] Gregson, N., \& Crewe, L. (2003). econd-hand cultures. Berg Publishers.

[20] Ha-Brookshire, J. a. (2009). Socially responsible consumer behavior? Exploring used clothing donation behavior. Clothing and Textiles Research Journal,, 27.

[21] Hamilton, A. (2007). Fast fashion, the remix-Time International (Canada Edition ed.).

[22] Hawley, J. M. (2006). Digging for diamonds: A conceptual framework for understanding reclaimed textile products. Clothing and Textiles Research Journal.

[23] Hiller, K. Y. (2010). Internal and external barriers to eco-conscious apparel acquisition. International Journal of Consumer Studies, 279-286.

[24] Jacobs, H., \& Bailey, J. (1982). Evaluating Participation in a Residential Recycling Program. Journal of Environmental Systems, 141-152.

[25] Jacoby, J., Berning, C., \& Dietvorst, T. (1977). What about disposition? The Journal of Marketing, 22-28.

[26] Joung, H., \& Park-Poaps, H. (2013). Factors motivating and influencing clothing behaviours. International Journal of Consumer Studies, 105-111.

[27] Kang, H., \& Schoenung, J. (2006). Economic Analysis of Electronic Waste Recycling:Modeling The Cost and Revenue of A Materials Recovery Facility in California. Environmental Science \& Technology, 1672-1680.

[28] Kim, H. (1995). Consumer response toward apparel products in advertisements.

[29] Kim, H., \& Damhorst, M. (1998). Environmental concern and apparel consumption. Clothing and Textiles Research Journal, 126-133.

[30] Koch, \& Domina. (1999). Consumer textile recycling as a means of solid waste reduction. Family and Consumer Sciences Research Journal, 3-17.

[31] McLaughlin, R. (n.d.). Fashion talks: Is $\$ 20$ for an outfit really cheaper? . Retrieved from Fashion talks: Is $\$ 20$ for an outfit really cheaper? : http://www.collajmag.com/668/fashiontalks-is-20-for\%0Aan-outfit-really-cheaper/

[32] Mohr, L., Webb, D., \& Harris, K. (2001). Do consumers expect companies to be socially responsible? The impact of corporate social responsibility on buying behaviour? Journal of Consumer Affairs.

[33] Morgan, L., \& Birtwistle, G. (2009). An investigation of young fashion consumer' s disposal habits. International Journal of Consumer Studies, 190-198.

[34] National Association of Resale and Thrift Shops- Industry statistics and trends. (2013). Retrieved from http://www.narts.org/i4a/pages/index.cfm?pageid

[35] Paden, N. a. (2005). Consumer product redistribution: disposition decisions and channel. Journal of Marketing Channels, 12, 105-123.

[36] Paden, N., \& Stell, R. (2005). Consumer product redistribution: disposition decisions and channel options. Journal of Marketing Channels, 12. 
[37] Rasband, J. (2006, 12 28). Renovating old clothes helps stretch the budget. Retrieved from Deseret News: https://www.deseret.com/2006/12/28/19992911/renovating-old-clothes-helpsstretch-the-budget

[38] Sampson, L. K. (2009). Consumer analysis of purchasing behavior for green apparel

[39] Saunders, S. (2010). "An exploratory study into the disposition behaviour of poor bottom-ofthepyramid urban consumers. Advances in Consumer Research, 37.

[40] Schiffman, L. K. (2010). Consumer behavior. New York: Pearson Global.

[41] Shim, S. (1995). Environmentalism and consumers' clothing disposal patterns: an exploratory study. Clothing and Textiles Research Journal, 13.

[42] Solomon, M. R. (2010). Consumer behavior: Buying, having, and being (9th ed.). Upper Saddle River.

[43] VeVerka, M. J. (1974). Inactive clothing of selectedfamilies.

[44] Winakor, G. (1969). The process of clothing consumption. Journal of Home Economics.

[45] Yee, W., Hassan, S., \& Ramayah, T. (2016). Sustainability and Philanthropic Awareness in Clothing Disposal Behavior Among Young Malaysian Consumers. SAGE Open. 